\title{
The effect of the DLTIDDSYWYRI motif of the human laminin $\alpha 2$ chain on implant osseointegration
}

Hyun Ki Kang ${ }^{\mathrm{a}, 1}$, O Bok Kim ${ }^{\mathrm{a}, 1}$, Seung-Ki Minº, , Sung Youn Jung ${ }^{\mathrm{a}}$, Da Hyun Jang ${ }^{\mathrm{a}}$, Taek-Ka Kwon ${ }^{\mathrm{c}}$, Byung-Moo Min, ${ }^{\mathrm{a}, *}$ In-Sung Yeo ${ }^{\mathrm{d}, *}$,

${ }^{\text {a }}$ Department of Oral Biochemistry and Program in Cancer and Developmental Biology, Dental Research Institute, Seoul National University School of Dentistry, 28 Yeonkun-Dong, Chongno-Ku, Seoul 110-749, Republic of Korea

${ }^{\mathrm{b}}$ Department of Oral and Maxillofacial Surgery, Seoul National University School of Dentistry, 28 Yeonkun-Dong, Chongno-Ku, Seoul 110-749, Republic of Korea

${ }^{c}$ Department of Dentistry, St. Vincent Hospital, Catholic University of Korea, Ji-Dong, Paldal-Ku, Suwon 442-723, Republic of Korea

${ }^{\mathrm{d}}$ Department of Prosthodontics and Dental Research Institute, Seoul National University School of Dentistry, 28 Yeonkun-Dong, Chongno-Ku, Seoul 110-749, Republic of Korea

${ }^{1}$ These authors contributed equally to this work.

* Corresponding author: Byung-Moo Min, Department of Oral Biochemistry, Seoul National University School of Dentistry, 28 Yeonkun-Dong, Chongno-Ku, Seoul 110-749, Republic of Korea. Tel.: +82 2740 8661; E-mail: bmmin@snu.ac.kr.

* Corresponding author: In-Sung Yeo, Department of Prosthodontics, Seoul National University School of Dentistry, 28 Yeonkun-Dong, Chongno-Ku, Seoul 110-749, Republic of Korea. Tel.: +82 2 2072 4110; E-mail: pros53@ @nu.ac.kr.

E-mail addresses: kang1978@snu.ac.kr (H.K. Kang), genibok@hanmail.net (O.B. Kim), snowmanonmars@gmail.com (S.-K. Min), jsy1618@snu.ac.kr (S.Y.Jung), jdahyun@ naver.com (D.H. Jang), tega95@naver.com (T.-K. Kwon), bmmin@snu.ac.kr (B.-M. Min), pros53@snu.ac.kr (I.S. Yeo). 


\section{ABSTRACT}

Considerable effort has been directed towards replacing lost teeth using tissue-engineering methods such as titanium implants. A number of studies have tried to modify bioinert titanium surfaces by coating them with functionally bioactive molecules for faster and stronger osseointegration than pure titanium surfaces. Recently, peptides were recognized as valuable scientific tools in the field of tissueengineering. The DLTIDDSYWYRI motif of the human laminin-2 $\alpha 2$ chain was previously reported to promote the attachment of various cell types; however, the in vivo effects of the DLTIDDSYWYRI motif on new bone formation have not yet been studied. To examine whether a laminin-2-derived peptide can promote osseointegration by accelerating new bone formation in vivo, we applied titanium implants coated with the DLTIDDSYWYRI motif in a rabbit tibia model. The application of the DLTIDDSYWYRI motif-treated implant to tibia wounds enhanced collagen deposition and alkaline phosphatase expression. It significantly promoted implant osseointegration compared with treatment with scrambled peptide-treated implants by increasing the bone-to-implant contact ratio and bone area. These findings support the hypothesis that the DLTIDDSYWYRI motif acts as an effective osseointegration accelerator by enhancing new bone formation.

Keywords: Laminin-2-derived peptide; Titanium implant; Tissue-engineering; Osseointegration; Bone-to-implant contact ratio 


\section{Introduction}

Considerable effort has been directed towards regenerating defective tissues using tissueengineering methods. Dental implants prepared from titanium (Ti) have been used to replace lost teeth through direct contact with surrounding bone, a process known as osseointegration. Modifications of Ti surfaces can cause faster and stronger osseointegration than on pure Ti surfaces [1-4]. Many researchers have tried to modify bioinert Ti surfaces of dental implants by coating them with bioactive molecules, such as calcium phosphate and bone morphogenic proteins (BMPs), to enhance osseointegration and to shorten the healing period of the bone. Although calcium phosphate-coated implants show superior early bone response and clinical success in prior studies [5-9], there are still some problems, including coating fragmentation and osteolysis due to wear particles. Similarly, using recombinant human BMP-2 is associated with complications such as early osteolysis and implant subsidence, although it usually results in excellent bone response at the interface between the bone and the implant [10].

To apply tissue-engineering methods for the treatment of patients, several problems, such as the functional activity and immune rejection of these engineered tissues, must first be resolved. Recently, peptides have been recognized as valuable scientific tools in the field of tissue-engineering because of their ability to improve the functional activity of the scaffold and to bypass or minimize immune rejection [11]. The surface modification of scaffolds with peptides has been tested extensively, and the application of these peptides to tissue regeneration is highly attractive.

The laminin $\alpha 2$ chain, which contains five carboxyl-terminal large globular (LG) domains, has cell binding activity $[12,13]$ and is reported to show cell attachment characteristics via integrins or by binding to syndecan-1. This property was expected to help the bone respond to the implant surface more favorably without the disadvantages of calcium phosphate and BMP [14-16]. Several synthetic peptides derived from the laminin $\alpha 2$ chain LG domains promote cell attachment $[15,16]$; however, investigations of laminin have mainly focused on epithelial attachment instead of bone-to-implant 
contact [17-19]. The potential roles of functionally bioactive peptides on osseointegration have not yet been elucidated.

The attachment of bone cells to implant surfaces is the first step in bone healing. Therefore, the cell attachment properties of laminin may be applied to Ti implant surfaces to improve biologic response at the bone-implant interface. We recently reported that the DLTIDDSYWYRI motif (amino acids 2221-2232; Ln2-P3) within the human laminin $\alpha 2$ LG1 domain mediates cell attachment through syndecan-1 by inducing phosphorylation and membrane localization of protein kinase C $\delta$ (Fig. 1). Furthermore, Ln2-P3 has a broad spectrum of cell-type attachment activity [15]. These studies suggest the hypothesis that a laminin-2-derived peptide, Ln2-P3, can promote new bone formation and osseointegration of Ti implants in vivo. In the present study, the effect of Ln2-P3 was examined in a rabbit implant model, as well as in human osteoblast-like cell culture system. 


\subsection{Preparation and characterization of the Ti discs and Ti implants}

Ti discs (20 $\mathrm{mm}$ and $50 \mathrm{~mm}$ in diameters, $0.5 \mathrm{~mm}$ thick) were prepared from commercially pure grade $4 \mathrm{Ti}$. Four types of disc surfaces were then prepared. First, pure Ti surfaces without any surface modification serving as controls. The second type of disc was a Ti surface that was sandblasted with large alumina $\left(\mathrm{Al}_{2} \mathrm{O}_{3}\right)$ particles and etched with hydrochloric acid solution (SLA surface; Dentium, Seoul, Korea), rinsed, ultrasonically washed, and dried. The third type of surface was an anodized Ti disc (Dentium) that was anodically oxidized in an aqueous electrolyte solution under a pulsed direct current field at $660 \mathrm{~Hz}$. The electrolyte was prepared by dissolving $0.15 \mathrm{M}$ calcium acetate monohydrate $\left[\mathrm{Ca}\left(\mathrm{CH}_{3} \mathrm{COO}\right)_{2} \cdot \mathrm{H}_{2} \mathrm{O}\right]$ and $0.02 \mathrm{M}$ calcium glycerophosphate $\left(\mathrm{CaC}_{3} \mathrm{H}_{7} \mathrm{O}_{6} \mathrm{P}\right)$ in doubledistilled water (DDW). Anodic oxidation was carried out at $270 \mathrm{~V}$ for $3 \mathrm{~min}$ in a water-cooled bath. The thickness of the oxide layer was approximately $2 \mu \mathrm{m}$. The fourth type of surface was calcium phosphorus (Ca-P)-coated. First, the Ti surface was sandblasted and acid-etched, like the third type of surface. Then, Ca-P thin film ( $300 \mathrm{~nm}$ thickness) was deposited on the surface with an electron beam. The Ca-P evaporants for electron beam deposition were prepared by sintering a mixed hydroxyapatite (Alfa Aesar, Johnson Matthey, London, UK) and calcium oxide (Sigma-Aldrich, St. Louis, MO, USA) powder at $1000^{\circ} \mathrm{C}$ for $2 \mathrm{~h}$. Finally, the surface was heat-treated at $350^{\circ} \mathrm{C}$ for $1 \mathrm{~h}$. Electron probe microanalysis (EPMA; JXA-8900R, Jeol, Tokyo, Japan) and confocal laser scanning microscopy (CLSM; LSM 5-Pascal, Carl Zeiss AG, Oberkochen, Germany) were performed to determine the chemical composition and roughness of each surface. The Ti implants $(3.5 \mathrm{~mm}$ in diameter, $8 \mathrm{~mm}$ long) were prepared from commercially pure grade $4 \mathrm{Ti}$ (Warrantec, Seoul, Korea). This pure, screw-shaped Ti implant was used without further surface modifications for an animal experiment in this study.

\subsection{Cells and peptides}




\subsection{Immobilization of synthetic peptides on culture plates, Ti discs and Ti implants}

Twenty-four-well plates (Nunc, Roskilde, Denmark) were coated with human placental laminin (1.3 $\mu \mathrm{g} / \mathrm{cm}^{2}$; Sigma-Aldrich), scrambled peptide $\left(21 \mu \mathrm{g} / \mathrm{cm}^{2} ; \mathrm{SP}\right)$, or Ln2-P3 $\left(21 \mu \mathrm{g} / \mathrm{cm}^{2}\right)$ by drying for $18 \mathrm{~h}$ at room temperature and then washing with phosphate-buffered saline (PBS). These values were the lowest concentrations at which the maximum level of attachment activity of PC12 cells was determined from dose-response curves [15]. The Ti discs (20 $\mathrm{mm}$ in diameter, $0.5 \mathrm{~mm}$ thick) were placed on 12-well culture plates, coated with synthetic peptides $\left(21 \mu \mathrm{g} / \mathrm{cm}^{2}\right)$ by drying for $18 \mathrm{~h}$ at room temperature, blocked with/without $1 \%$ heat-inactivated bovine serum albumin (BSA) for $1 \mathrm{~h}$ at $37^{\circ} \mathrm{C}$, and then washed with PBS. The Ti implants were placed on $0.2 \mathrm{ml}$ PCR tubes and coated with synthetic peptides $\left(1 \mathrm{mg} / \mathrm{cm}^{2}\right)$ by drying for $7 \mathrm{~d}$ in a vacuum at room temperature. To determine the coating efficiency of the synthetic Ln2-P3 onto the Ti implant, peptide-coated Ti implants were transferred to a new PCR tube and washed twice for $15 \mathrm{~min}$ in distilled water at room temperature. The amount of remaining peptide was determined using a $\mathrm{BCA}^{\mathrm{TM}}$ protein assay kit (Thermo Scientific, Rockford, IL, USA).

\subsection{Cell attachment and spreading assays}




\subsection{Time-dependent cellular adhesion profiling}

The xCELLigence system (Roche Applied Science, Mannheim, Germany) is a real-time cell analyzer that evaluates cell attachment. The method by which the system measures cell attachment has previously been described [21]. Each well was equilibrated with $100 \mu \mathrm{l}$ of serum-free DMEM for 15 min. MG63 cells $\left(2 \times 10^{4}\right.$ cells/well $)$ were seeded onto SP $\left(21 \mu \mathrm{g} / \mathrm{cm}^{2}\right)$ - or Ln2-P3 $\left(21 \mu \mathrm{g} / \mathrm{cm}^{2}\right)$ coated wells of an E-plate (Roche Applied Science). The system measured the increased impedance 
and converted it to another variable, the cell index. An increase of the cell index implies increase of cell attachment to the well. The cell indices of MG63 cells were monitored every min for $3 \mathrm{~h}$, and then were measured every $10 \mathrm{~min}$ for $2 \mathrm{~h}$.

\subsection{Scanning electron microscopy}

SEM was used to examine the cell attachment of MG63 cells cultured onto the Ti surfaces. Ti discs (20 $\mathrm{mm}$ in diameter, $0.5 \mathrm{~mm}$ thick) were placed in 12-well plates, with one disc per well. The culture plates containing the Ti discs were coated with/without synthetic peptides, washed once with PBS, and seeded with $1 \mathrm{ml}$ of a cell suspension containing 1 X $10^{5}$ cells. The cultures were incubated for $1 \mathrm{~h}$ at $37^{\circ} \mathrm{C}$ in $5 \% \mathrm{CO}_{2}$. The loosely adherent or unbound cells from the experimental wells were removed by aspiration, the wells were washed once with PBS, and the remaining bound cells were fixed in $4 \%$ paraformaldehyde in PBS for 15 min. The fixative was then aspirated. After washing in the buffer, the Ti discs were dehydrated in a graded series of ethanol solutions. After critical point drying (HCP-2, Hitachi, Tokyo, Japan), the samples were sputtered with Au/Pd using an SEM coating system (Quorum Q150T-S, Quorum Technologies, West Sussex, UK), and the probes were examined by field emission-SEM (FE-SEM; Hitachi S-4700, Hitachi) at $15 \mathrm{kV}$. To ensure a representative count, each Ti disc was divided into quarters and one field per each quarter was photographed using FESEM and counted. Averages and standard deviations were calculated from three independent experiments.

\subsection{Alkaline phosphatase assay}

The 60-mm culture dishes containing the Ti discs $(50 \mathrm{~mm}$ in diameter, $0.5 \mathrm{~mm}$ thick) were coated with SP or Ln2-P3 $\left(21 \mu \mathrm{g} / \mathrm{cm}^{2}\right)$ by drying for $18 \mathrm{~h}$ in a vacuum at room temperature and then washed once with PBS. MG63 cells were detached by trypsin digestion and $3 \mathrm{ml}$ of a cell suspension 
containing $8 \times 10^{5}$ cells were placed on each Ti surface and on control plastic dishes. The cells were cultured for $1 \mathrm{~d}$ and $3 \mathrm{~d}$ at $37^{\circ} \mathrm{C}$ in a $5 \% \mathrm{CO}_{2}$ atmosphere. The medium was changed every $2 \mathrm{~d}$. At the end of the incubation, Ti discs were transferred to new 60-mm culture dishes. Alkaline phosphatase (ALP) activity was assayed in a reaction mixture composed of $8 \mathrm{mM} p$-nitrophenyl phosphate (Calbiochem, San Diego, CA, USA), $0.1 \mathrm{M}$ glycine-NaOH buffer, $\mathrm{pH} 10.4,150 \mathrm{mM} \mathrm{MgCl} 2,150 \mathrm{mM}$ $\mathrm{ZnCl}_{2}$, and $15 \mu \mathrm{l}$ of cytosol in a final reaction volume of $90 \mu \mathrm{l}$. The reaction was incubated for $1 \mathrm{~h}$ in a water bath at $37^{\circ} \mathrm{C}$ and was terminated by the addition of $210 \mu \mathrm{l}$ of $0.25 \mathrm{~N} \mathrm{NaOH}$. The absorbance was measured at $405 \mathrm{~nm}$ in a Bio-Rad Model 550 microplate reader (Bio-Rad). Enzyme activity was expressed as nmol $p$-nitrophenol product per min per $\mu \mathrm{g}$ of protein.

\subsection{Real-time RT-PCR}

Total RNA was isolated using the RNeasy Mini Kit (Qiagen, Valencia, CA, USA) according to the manufacturer's instructions. After the RNA was denatured by $70^{\circ} \mathrm{C}$ incubation for 10 min and kept on ice for 5 min, cDNA was prepared using SuperScript ${ }^{\mathrm{TM}}$ III Reverse Transcriptase (Invitrogen, Carlsbad, CA, USA) and a random hexamer (Fermentas, Hanover, MD, USA), and then subjected to real-time PCR amplification using SYBR $^{\circledR}$ Green PCR Master Mix (Takara, Shiga, Japan) that contained a $300 \mathrm{nM}$ final concentration of each primer and cDNA, corresponding to $17 \mathrm{ng}$ of total RNA. Real-time PCR was performed using the 7300 Real-time PCR System (Applied Biosystems). Primer sequences were designed using Primer Express ${ }^{\circledR}$ Software version 3.0 (Applied Biosystems). The PCR primers used were as follows: ALP, 5'-CCCACGTCGATTGCATCTCT-3' (sense) and 5'AGTAAGGCAGGTGCCAATGG-3' (antisense); bone sialoprotein, 5'AAGGCTACGATGGCTATGATGGT-3' (sense) and 5'-AATGGTAGCCGGATGCAAAG-3' (antisense); type I collagen, 5'-CAAAAAATGGGAGACAATTTCACA-3' (sense) and 5'TCATGTTCGGTTGGTCAAAGAT-3' (antisense); Cbfa-1， 5'-GCCTTCAAGGTGGTAGCCC-3' (sense) and 5'-CGTTACCCGCCATGACAGTA-3' (antisense); osteocalcin, 5'- 
GAAGCCCAGCGGTGCA-3' (sense) and 5'-CACTACCTCGCTGCCCTCC-3' (antisense); osteonectin, 5'-TACATCGGGCCTTGCAAATAC-3' ${ }^{\prime}$ (sense) and 5' $^{\prime}$ GGGTGACCAGGACGTTCTTG-3' (antisense); osteopontin, 5'-CAGCCTTCTCAGCCAAACG-3' (sense) and 5'-TAACTGGTATGGCACAGGTGATG-3' (antisense); and hypoxanthine phosphoribosyltransferase 1 (HPRT1), 5'-GGTCAGGCAGTATAATCCAAAGA-3' (sense) and 5'GGGCATATCCTACAACAAACT-3' (antisense). After incubation at $95^{\circ} \mathrm{C}$ for $4 \mathrm{~min}$, PCR cycling conditions consisted of 40 cycles at $95^{\circ} \mathrm{C}$ for 15 seconds, $60^{\circ} \mathrm{C}$ for 20 seconds, and $72^{\circ} \mathrm{C}$ for 34 seconds. To analyze the data, cycle threshold values were determined by automated threshold analysis with Sequenced Detection Software version 1.4, after which the calculated cycle threshold values were exported to Microsoft Excel for analysis. The relative expressions of each target mRNA were calculated using the comparative cycle threshold method according to the manufacturer's protocol (Applied Biosystems).

\subsection{Animal experiments}

We used nine male New Zealand white rabbits that ranged from one- to two-years-old (2.5-3.5 kg) for animal experiments. The rabbits showed no signs of disease. The anesthetic procedures, preparation of the surgical site, and drilling for implant insertion were performed as described previously $[9,22,23]$. Drilling was done at the upper cortex only. The diameter of the holes drilled for implant insertion was $3.2 \mathrm{~mm}$. Twenty seven pure, screw-shaped Ti implants $(3.5 \mathrm{~mm}$ in diameter, 8 mm long) were used. Among these, 9 implants were treated with SP and another 9 with Ln2-P3, as mentioned above. The other 9 implants, which had pure Ti surfaces without further surface modifications, served as negative controls. Each rabbit received three implants, which included all three groups. Two implants were inserted in the right tibia and one implant was placed in the left tibia. The implants were assigned according to a 3 by 3 Latin square (Fig. 2). The implants penetrated the first cortical layer only. The periosteum and fascia were sutured with 4-0 chromic gut, and the skin 
was sutured with 4-0 silk (Ethicon, Somerville, NJ, USA). This study was approved by the Animal Research Committee of Seoul National University, Seoul, Korea. All experiments were performed in accordance with the guidelines of the Institute of Laboratory Animal Resources at Seoul National University (approval number: SNU-111123-2).

\subsection{Histological assessment}

The animals were anesthetized and sacrificed by an intravenous administration of potassium chloride for histomorphometry. Three rabbits were sacrificed at each study interval of one, two, and four weeks after implant insertion. The implants were surgically removed en bloc with an adjacent bone collar and immediately fixed in $4 \%$ neutral formaldehyde. The histomorphometric specimens were prepared as described previously [9,24,25]. Bone-to-implant contact (BIC) ratio and bone area were measured in the best three consecutive threads using a light microscope (Olympus BX microscope, Olympus, Tokyo, Japan) and image analysis software (Kappa Imagebase, Kappa Optoelectronics GmbH, Gleichen, Germany). The measurements were performed at 100× magnification.

In addition, the sections were stained using modified Goldner's Masson trichrome staining technique and ALP histochemistry. We assayed collagen deposition using modified Goldner's Masson trichrome staining because it is adequate to detect collagen deposition of the undecalcified bone specimens [26]. Briefly, the sections were stained in Weigert hematoxylin for 20 min, washed in running water for $5 \mathrm{~min}$, and rinsed in double-distilled water (DDW). Then, the sections were stained in Blebrich scarlet-acid fuchsin solution for $20 \mathrm{~min}$ and placed in $1 \%$ acetic acid solution for $5 \mathrm{~min}$. The slides were placed in phosphomolybdic-phosphotungstic acid solution for 5 min followed by $1 \%$ acetic acid solution for $3 \mathrm{~min}$. The sections were transferred into Aniline Blue solution for 5 min and placed in $1 \%$ acetic acid solution. After washed and dehydrated, the slides were examined at $100 \times$ magnification using the light microscope. New bone or osteoid is known to be stained red using this method [26]. Next, ALP histochemistry was performed as previously described [27]. Briefly, the 
sections were stained in nitroblue tetrazolium choloride/5-bromo-4-choloro-3-indolyl phosphate toluidine (NBT/BCIP) salt solution at $37^{\circ} \mathrm{C}$ for $24 \mathrm{~h}$. The slides were counterstained with methyl green for 1 min and rinsed and examined at 200× magnification using the light microscope.

\subsection{Statistical evaluations}

Results were compared by analysis of variance (ANOVA). When significant differences were found, pairwise comparisons were performed using Scheffe's adjustments. In the animal experiments, statistical analyses of BIC ratio and bone area data were performed by Kruskal-Wallis tests. $P$-values less than 0.05 were considered significant. 


\section{Results}

\subsection{Effect of Ln2-P3 on cell attachment and spreading}

We previously found that the Ln2-P3 within the human laminin $\alpha 2$ LG1 domain is a major ligand for syndecan-1, which mediates cell attachment through the PKC $\delta$ signaling pathway in PC12 cells [15]. Because osteoblasts play a central role in bone formation and regeneration, and Ln2-P3 has a broad spectrum of cell-type activity in the attachment of normal human epidermal keratinocytes, normal human dermal fibroblasts, CV-1, and NIH/3T3 [15], the effect of Ln2-P3 on cell attachment and spreading of osteoblast-like HOS and MG63 cells were examined to determine whether Ln2-P3 could be used in biomedical applications, particularly for enhancing the osseointegration of $\mathrm{Ti}$ implants. The attachment of MG63 and HOS cells was evaluated using a cell attachment assay in serum-free medium. As hypothesized, human placental laminin strongly promoted cell attachment (Fig. 3A and B) and the spreading (Fig. 3D) of HOS and MG63 cells. Ln2-P3 had a strong effect on cell attachment relative to BSA or SP in HOS and MG63 cells. In fact, cell attachment to Ln2-P3 was similar to that observed in human placental laminin (Fig. 3A and B). To further confirm the enhancement of Ln2-P3-dependent cell attachment activity, impedance-based time-dependent cell response profiles were determined and showed a strong association with cell attachment assay (Fig. 3C). To further evaluate the attachment activity of Ln2-P3, we determined whether adherent cells were tethered to the substrate or spread over the Ln2-P3. Similar to human placental laminin, Ln2-P3 had a strong effect on cell spreading compared with the BSA and a SP in MG63 cells (Fig. 3A and D). Although HOS cell spreading on Ln2-P3 was reduced by approximately $20 \%$ compared to laminin, Ln2-P3 showed significantly higher cell spreading than BSA or SP (Fig. 3A and D). These results support the hypothesis that Ln2-P3 is functionally active in promoting the cellular responses of osteoblast-like cells, which is important for bone formation and regeneration. 
The EPMA and CLSM analyses showed that the chemical composition and roughness of each surface were similar to those of previous studies (Table 1) [9,22-25]. The attachment of MG63 cells on modified Ti surfaces was evaluated using a SEM in serum-free medium. MG63 cells adhered to anodized and (Ca-P)-coated Ti surfaces but only weakly attached to SLA and pure Ti surfaces (Fig. 4A and B). When Ln2-P3 was treated onto the anodized Ti surface, the coated surface was expected to show the best result in cellular response. Pure Ti surfaces have an advantage in that additional modification procedures are unnecessary when the surface is treated with functionally bioactive peptides. Ln2-P3-treated anodized and pure Ti surfaces were, therefore, compared in this study. The attachment of MG63 cells on Ln2-P3-treated pure Ti surfaces was significantly higher than that of SPtreated pure Ti surfaces and pure Ti surfaces without peptide coating, but Ln2-P3-treated anodized Ti surfaces did not show such an effect (Fig. 4C and D). Unexpectedly, there was no significant difference in cell attachment between the Ln2-P3-treated anodized and Ln2-P3-treated pure Ti surfaces (Fig. 4D). Therefore, we selected the pure Ti surface as a base that was treated with Ln2-P3 in the ALP assay, real-time RT-PCR, and animal experiments.

\subsection{Effect of Ln2-P3 on osteogenic gene expression}

To further examine the osteogenic potential of Ln2-P3, the expressions of type I collagen, bone sialoprotein, osteocalcin, and Cbfa-1 were determined in MG63 cells seeded onto Ln2-P3-treated pure Ti surfaces for $1 \mathrm{~d}$ and $7 \mathrm{~d}$ by real-time RT-PCR analysis with various primers (Table 2). Previous studies reported that osteonectin, type I collagen, and osteopontin are early/intermediate markers for osteogenesis, while Cbfa-1, bone sialoprotein, and osteocalcin are intermediate/late markers [28]. When MG63 cells were cultured onto the Ti disc alone and the SP- and Ln2-P3-treated 
Ti discs for $1 \mathrm{~d}$, the Ln2-P3-treated cells showed similar (bone sialoprotein and Cbfa-1) or slightly changed (type I collagen and osteocalcin) expression levels of all four osteogenic markers as compared to their untreated and SP-treated counterparts (Fig. 5). However, this analysis revealed significantly higher expression levels of all four osteogenic markers in Ln2-P3-treated MG63 cells at day 7 compared to untreated and SP-treated cells (Fig. 4). These results suggest that Ln2-P3 has an osteogenic effect on MG63 cells.

\subsection{Effect of Ln2-P3 on ALP expression}

ALP is widely used as an early/intermediate marker of osteogenesis [29,30], and increased ALP activity is often associated with osteoblastic differentiation [31]. To investigate the effect of Ln2-P3 on in vitro osteogenesis, Ln2-P3-treated osteoblast-like cells were characterized through the detection of ALP transcription/activity. MG63 cells seeded onto the Ln2-P3-treated pure Ti discs for $1 \mathrm{~d}$ and $7 \mathrm{~d}$ showed significantly higher expressions of ALP than those of the untreated and SP-treated cells, which was determined by real-time RT-PCR (Fig. 6A). Moreover, ALP enzyme activity in MG63 cells seeded onto the Ln2-P3-treated Ti discs for $1 \mathrm{~d}$ was significantly increased compared with those of the untreated and SP-treated cells (Fig. 6B). The ALP activity at day 3 was also significantly increased by the Ln2-P3 compared to the untreated and SP-treated cells, but the ALP activity was notably lower than that of their counterpart at day 1. Together, these data indicate that Ln2-P3-treated osteoblast-like cells are positive for ALP activity.

\subsection{Effect of Ln2-P3 on osseointegration}

There was no inflammation of the bone near the inserted implants at the time of sacrifice in experimental animals. In light microscopy, no inflammatory cells were found around the implants (Fig. 7A, B and C). Newly formed cancellous bone was found between the threads of the Ln2-P3- 
treated implant after 1 week of implant insertion, while little new bone was formed in the pure Ti implant and SP-treated implant (Fig. 7A). More cancellous bone was formed after 2 weeks of healing, although new bone tissue was still slowly forming in the pure Ti implant (Fig. 7B). New cortical bone was formed in all groups after 4 weeks of implant placement, and the mature bone was anchored to the implant surface (Fig. 7C). Fig. 7D and E show the BIC ratio and bone area in each group. Whether the implant was installed on the right or left side did not affect the results (data not shown). As expected, the healing periods had effects on both the BIC ratio and bone area, with longer healing times corresponding to higher BIC ratios. SP-treated implants had the lowest BIC ratio at 4 weeks after implant insertion; however, Ln2-P3-treated implants showed significantly higher BIC ratio than SP-treated implants after 4 weeks of healing. No significant differences in BIC ratio were found at either 1 or 2 weeks after implant insertion (Fig. 7D). Significantly higher bone area values were found in the Ln2-P3-treated implant group at 1 week after implant placement. There were no significant differences in bone area at week 2 or 4 during the healing periods (Fig. 7E).

To confirm the new bone formation around the implants, we determined collagen deposition in the threads of the implant using modified Goldner's Masson trichrome staining. Modified Goldner's Masson trichrome stain is an excellent bone stain because it provides good distinction of newly formed osteoid which stains red. The histological sections showed strong red staining of osteoid collagen deposition in the threads of the Ln2-P3-treated implant compared to the pure Ti implants and SP-treated implants after 1 week (Fig. 8A, left). More collagen deposition was found between the threads of the SP- and Ln2-P3-treated implants after 2 weeks of implant insertion, while little collagen deposition was formed in the pure Ti implants (Fig. 8A, middle). After 4 weeks of healing, similar amounts of collagen deposition were found in all three implant groups (Fig. 8A, right). Next, to detect osteoblasts in the transplanted site, we used ALP histochemistry which was marked increased in Ln2P3-treated implants compared with the other implants after 1 week of healing (Fig. 8B, left). Although ALP expression was also found in the threads of the pure Ti implants and SP-treated implants after 2 and 4 weeks after implant insertion, the ALP expression was more definitive in the Ln2-P3-treated 
implants (Fig. 8B, middle and right). Together, these data demonstrate that Ln2-P3 has an osteogenic effect in vivo. 


\section{Discussion}

We explored the potential of a peptide to function as an effective osseointegration accelerator of implant materials by determining its effect on BIC ratio and bone area. A laminin-2-derived peptide, Ln2-P3, promoted initial cell attachment and the spreading of osteoblast-like cells in vitro. Because the initial cell attachment and spreading may be important for wound healing, our finding that Ln2-P3 induced significant increases of cellular response in osteoblast-like cells, which are the major cell types inducing new bone formation and regeneration, was highly meaningful. Since the BIC ratio is important in osseointegration and for the long-lasting clinical survival of dental implants [32], in this study we investigated the potential for a peptide to accelerate early stage osseointegration by determining the BIC ratio and bone area. Ln2-P3 promoted the early stage of osseointegration by increasing the BIC ratio and enhancing bone area in vivo, as well as increasing cell attachment and spreading of osteoblast-like cells in vitro. These results were confirmed in the modified Goldner's Masson trichrome staining of collagen and ALP histochemistry of osteoblasts in undecalcified bone sections of Ln2-P3-treated Ti implants.

Because short peptides induce cellular responses without immunoreactivity $[11,33,34]$, the application of these peptides to tissue regeneration is highly attractive. Furthermore, recent studies have investigated the biological activities of peptides in tissues and organs [34-37], and have strongly suggested that peptides are valuable scientific tools. In order for peptides to be used in biomedical applications, the antigenicity of the peptides and their effects on the inflammatory phase of wound healing must be understood. Acute inflammation is the initial response of the body to harmful stimuli and serves to remove foreign bodies and dead or devitalized tissues, as well as to prevent infection [36]. In this study, to bypass or minimize immune rejection, we used Ln2-P3, a short synthetic peptide of 12 amino acid residues which was previously identified as a biologically active minimal core sequence (data not shown) [15]. Our previous report demonstrated that the Ln2-P3 peptide coated with scaffolds does not display any differences in the number of infiltrating inflammatory cells 
compared to vehicle [38]. This finding may indicate that Ln2-P3 has low or no antigenicity.

The optimal roughness of the implant surface for bone response is about $1.5 \mu \mathrm{m}$ (moderately rough; $1.0-2.0 \mu \mathrm{m})$ in $S_{a}[4,25,39,40]$. An $S_{a}$ value of $1.5 \mu \mathrm{m}$ was obtained from a Ti surface that was blasted with $\mathrm{Al}_{2} \mathrm{O}_{3}$ particles $[4,39,40]$, and the optimal $\mathrm{S}_{\mathrm{a}}$ value is different in SLA, anodized, and CaP-coated Ti surfaces. In this study, the FE-SEM analysis showed that a greater number of MG63 cells was attached on the anodized surface than on the SLA surface, despite the fact that the roughness of the anodized surface was less than $1.0 \mu \mathrm{m}$ and the SLA surface was moderately rough $(1.73 \mu \mathrm{m})$. The morphologies and chemical compositions of the investigated surfaces were also considered to affect cell attachment $[1,25]$. Further studies are needed to determine the optimal roughness of each surface to promote cellular responses in osteoblast-like cells.

The selection of the base surface of implant materials is an important factor for effective osseointegration. The Ln2-P3-treated, anodized Ti surface was expected to show the best result in cellular responses; however, in this study, a pure Ti surface was selected an alternative base surface for peptide coating because it required no additional surface modification before peptide coating. The cellular activity of the Ln2-P3-treated surfaces was evaluated without blocking the base surfaces because the cellular activity of the pure Ti surface was higher than that of the BSA-blocked Ti surface (data not shown), and a preparation of peptide-treated Ti implants without blocking was more appropriate than implants with blocking for use in clinical contexts. When Ln2-P3-treated, anodized and Ln2-P3-treated pure Ti surfaces without blocking were compared, the differences in cell attachment activity between the anodized and pure Ti surfaces at day 7 were masked by Ln2-P3 treatment. The Ln2-P3 peptide, which was derived from the laminin $\alpha 2$ LG1 domain to promote cell attachment, had a stronger effect on osteoblast-like cell attachment than the type of the implant base surface that was treated with Ln2-P3.

Our evaluation of ALP activity and the levels of osteogenic marker genes further confirmed that Ln2-P3-treated Ti surfaces may be beneficial for bone healing and osseointegration. More active bone formation was anticipated around Ln2-P3-treated implants because the expression levels of osteogenic 
markers were elevated [28-30]. Such expectations were confirmed in the in vivo experiments. The Ln2-P3-treated implant was superior to the other investigated surfaces in terms of BIC ratio at 4 weeks after implant insertion and bone area at 1 week. Moreover, it was found that ALP expression during the experimental period and osteoid collagen deposition at 1 week were more definitive in the Ln2-P3-treated implants than the pure Ti implants and SP-treated implants. These results are consistent with those of previous reports, which demonstrate that laminin-treated ceramic scaffolds activate osteogenesis by promoting the attachment of osteoprogenitor cells $[41,42]$. Our study may clarify the role of Ln2-P3 by evaluating both the in vitro and in vivo bone cell responses around implants that are treated with laminin-derived peptide. In addition, Ln2-P3 is considered to stimulate osteoblastic differentiation by increasing ALP activity [31]. The promotion of osteoblast-like cell attachment and spreading, increased ALP activity, higher expression levels of the osteogenic marker genes, and superior histomorphometric results in vivo suggest that Ln2-P3 may be used as an implant surface modifier to accelerate the bone healing process and to decrease the overall treatment time of implant therapy. Further studies are needed to compare Ln2-P3-treated surfaces with other modified surfaces. 


\section{Conclusions}

In this study, the effect of the DLTIDDSYWYRI motif of the human laminin $\alpha 2$ chain was examined in a rabbit tibia model and in osteoblast-like cells in culture. Ln2-P3 promoted osteoblastlike cell attachment and spreading in the cytocompatibility assessment. Anodized and pure Ti surfaces treated with Ln2-P3 were functionally active in promoting both cell attachment and spreading, as well as enhancing ALP activities and expressing osteogenic marker genes in osteoblast-like cells. In an osseointegration assessment, the pure Ti implant coated with Ln2-P3 was effective for promoting osseointegration by enhancing the BIC ratio and bone area in a rabbit tibia model. Increased histochemical staining of collagen and ALP expression of osteoblasts were confirmed in the Ln2-P3treated $\mathrm{Ti}$ implants, indicating that Ln2-P3 is a good candidate for improving the biological performance of Ti implants and reducing the time required before the loading of load-bearing, bone contacting devices.

\section{Acknowledgments}

We thank Drs. Frank Yu and Jae-Il Lee for their critical comments and suggestions. This work was supported by the Basic Science Research Program through the National Research Foundation of Korea (NRF) funded by MEST (Grant No. 2011-0007662) and the Mid-career Researcher Program through NRF, funded by MEST (Grant No. 2010-0014662). 


\section{References}

[1] Cooper LF. A role for surface topography in creating and maintaining bone at titanium endosseous implants. J Prosthet Dent 2000;84:522-34.

[2] Ellingsen JE. Surface configurations of dental implants. Periodontol 2000 1998;17:36-46.

[3] Ellingsen JE, Johansson CB, Wennerberg A, Holmen A. Improved retention and bone-tolmplant contact with fluoride-modified titanium implants. Int J Oral Maxillofac Implants 2004;19:659-66.

[4] Wennerberg A, Albrektsson T, Andersson B, Krol JJ. A histomorphometric and removal torque study of screw-shaped titanium implants with three different surface topographies. Clin Oral Implants Res 1995;6:24-30.

[5] Harada Y, Wang JT, Doppalapudi VA, Willis AA, Jasty M, Harris WH, et al. Differential effects of different forms of hydroxyapatite and hydroxyapatite/tricalcium phosphate particulates on human monocyte/macrophages in vitro. J Biomed Mater Res 1996;31:19-26.

[6] Lee JJ, Rouhfar L, Beirne OR. Survival of hydroxyapatite-coated implants: a meta-analytic review. J Oral Maxillofac Surg 2000;58:1372-9.

[7] Rungcharassaeng K, Lozada JL, Kan JY, Kim JS, Campagni WV, Munoz CA. Peri-implant tissue response of immediately loaded, threaded, HA-coated implants: 1-year results. J Prosthet Dent 2002;87:173-81.

[8] Sun L, Berndt CC, Gross KA, Kucuk A. Material fundamentals and clinical performance of plasma-sprayed hydroxyapatite coatings: a review. J Biomed Mater Res 2001;58:570-92.

[9] Yeo IS, Han JS, Yang JH. Biomechanical and histomorphometric study of dental implants with different surface characteristics. J Biomed Mater Res B Appl Biomater 2008;87:303-11.

[10] Kang JD. Another complication associated with rhBMP-2? Spine J 2011;11:517-9.

[11] Berke Z, Palmer S, Bergman T, Wester D, Svedmyr J, Linder S, et al. A short peptide eluted from the $\mathrm{H}-2 \mathrm{~Kb}$ molecule of a polyomavirus-positive tumor corresponds to polyomavirus large $\mathrm{T}$ antigen peptide at amino acids 578 to 585 and induces polyomavirus-specific immunity. J Virol 
1996;70:3093-7.

[12] Suzuki N, Yokoyama F, Nomizu M. Functional sites in the laminin $\alpha$ chains. Connect Tissue Res $2005 ; 46: 142-52$

[13] Vuolteenaho R, Nissinen M, Sainio K, Byers M, Eddy R, Hirvonen H, et al. Human laminin M chain (merosin): complete primary structure, chromosomal assignment, and expression of the $\mathrm{M}$ and A chain in human fetal tissues. J Cell Biol 1994;124:381-94.

[14] Hoffman MP, Nomizu M, Roque E, Lee S, Jung DW, Yamada Y, et al. Laminin-1 and laminin-2 G-domain synthetic peptides bind syndecan-1 and are involved in acinar formation of a human submandibular gland cell line. J Biol Chem 1998;273:28633-41.

[15] Jung SY, Kim JM, Kang HK, Jang da H, Min BM. A biologically active sequence of the laminin a2 large globular 1 domain promotes cell adhesion through syndecan-1 by inducing phosphorylation and membrane localization of protein kinase C $\delta$. J Biol Chem 2009;284:3176475.

[16] Nomizu M, Song SY, Kuratomi Y, Tanaka M, Kim WH, Kleinman HK, et al. Active peptides from the carboxyl-terminal globular domain of laminin $\alpha 2$ and Drosophila $\alpha$ chains. FEBS Lett 1996;396:37-42.

[17] Mackenzie IC, Tonetti MS. Formation of normal gingival epithelial phenotypes around osseointegrated oral implants in humans. J Periodontol 1995;66:933-43.

[18] Roessler S, Born R, Scharnweber D, Worch H, Sewing A, Dard M. Biomimetic coatings functionalized with adhesion peptides for dental implants. J Mater Sci Mater Med 2001;12:871-7.

[19] Werner S, Huck O, Frisch B, Vautier D, Elkaim R, Voegel JC, et al. The effect of microstructured surfaces and laminin-derived peptide coatings on soft tissue interactions with titanium dental implants. Biomaterials 2009;30:2291-301.

[20] Kim JM, Park WH, Min BM. The PPFLMLLKGSTR motif in globular domain 3 of the human laminin-5 $\alpha 3$ chain is crucial for integrin $\alpha 3 \beta 1$ binding and cell adhesion. Exp Cell Res 2005;304:317-27. 
[21] Malkoc S, Ozturk F, Corekci B, Bozkurt BS, Hakki SS. Real-time cell analysis of the cytotoxicity of orthodontic mini-implants on human gingival fibroblasts and mouse osteoblasts. Am J Orthod Dentofacial Orthop 2012;141:419-26.

[22] Choi JY, Lee HJ, Jang JU, Yeo IS. Comparison between bioactive fluoride modified and bioinert anodically oxidized implant surfaces in early bone response using rabbit tibia model. Implant Dent 2012;21:124-8.

[23] You C, Yeo IS, Kim MD, Eom TK, Lee JY, Kim S. Characterization and in vivo evaluation of calcium phosphate coated cp-titanium by dip-spin method. Curr Appl Phys 2005;5:501-6.

[24] Dohan Ehrenfest DM, Vazquez L, Park YJ, Sammartino G, Bernard JP. Identification card and codification of the chemical and morphological characteristics of 14 dental implant surfaces. $\mathbf{J}$ Oral Implantol 2011;37:525-42.

[25] Wennerberg A, Albrektsson T. On implant surfaces: a review of current knowledge and opinions. Int J Oral Maxillofac Implants 2010;25:63-74.

[26] Cruber HE. Adaptations of Goldner's Masson trichrome stain for the study of undecalcified plastic embedded bone. Biotech Histochem 1992; 67:30-4.

[27] Yoshiki S, Umeda T, Kurahashi Y. An effective reactivation of alkaline phosphatase in hard tissues completely decalcified for light and electron microscopy. Histochemie 1972;29:296-304.

[28] zur Nieden NI, Price FD, Davis LA, Everitt RE, Rancourt DE. Gene profiling on mixed embryonic stem cell populations reveals a biphasic role for $\beta$-catenin in osteogenic differentiation. Mol Endocrinol 2007;21:674-85.

[29] Fromigue O, Hamidouche Z, Chateauvieux S, Charbord P, Marie PJ. Distinct osteoblastic differentiation potential of murine fetal liver and bone marrow stroma-derived mesenchymal stem cells. J Cell Biochem 2008;104:620-8.

[30] Kang HK, Roh S, Lee G, Hong SD, Kang H, Min BM. Osteogenic potential of embryonic stem cells in tooth sockets. Int J Mol Med 2008;21:539-44.

[31] Turksen K, Bhargava U, Moe HK, Aubin JE. Isolation of monoclonal antibodies recognizing rat 
bone-associated molecules in vitro and in vivo. J Histochem Cytochem 1992;40:1339-52.

[32] Albrektsson T, Branemark PI, Hansson HA, Lindstrom J. Osseointegrated titanium implants. Requirements for ensuring a long-lasting, direct bone-to-implant anchorage in man. Acta Orthop Scand 1981;52:155-70.

[33] René A, Jackson RN. Gale encyclopedia of nursing and allied health, Infection control information on healthline. Detroit: The Gale Group Inc; 2002.

[34] Min SK, Lee SC, Hong SD, Chung CP, Park WH, Min BM. The effect of a laminin-5-derived peptide coated onto chitin microfibers on re-epithelialization in early-stage wound healing. Biomaterials 2010;31:4725-30.

[35] Figiel M, Allritz C, Lehmann C, Engele J. Gap junctional control of glial glutamate transporter expression. Mol Cell Neurosci 2007;35:130-7.

[36] Gurtner GC, Werner S, Barrandon Y, Longaker MT. Wound repair and regeneration. Nature 2008;453:314-21.

[37] Wright CS, van Steensel MA, Hodgins MB, Martin PE. Connexin mimetic peptides improve cell migration rates of human epidermal keratinocytes and dermal fibroblasts in vitro. Wound Repair Regen 2009;17:240-9.

[38] Seo SY, Min SK, Bae HK, Roh D, Kang HK, Roh S, et al. A laminin-2-derived peptide promotes early-stage peripheral nerve regeneration in a dual-component artificial nerve graft. J Tissue Eng Regen Med 2012. http://dx.doi.org/10.1002/term.1468.

[39] Wennerberg A, Albrektsson T, Lausmaa J. Torque and histomorphometric evaluation of c.p. titanium screws blasted with 25- and 75-microns-sized particles of Al2O3. J Biomed Mater Res 1996;30:251-60.

[40] Wennerberg A, Hallgren C, Johansson C, Danelli S. A histomorphometric evaluation of screwshaped implants each prepared with two surface roughnesses. Clin Oral Implants Res 1998;9:119.

[41] Dennis JE, Caplan AI. Porous ceramic vehicles for rat-marrow-derived (Rattus norvegicus) 
osteogenic cell delivery: effects of pre-treatment with fibronectin or laminin. J Oral Implantol $1993 ; 19: 106-15$

[42] Yoshikawa M, Tsuji N, Shimomura Y, Hayashi H, Ohgushi H. Osteogenesis depending on geometry of porous hydroxyapatite scaffolds. Calcif Tissue Int 2008;83:139-45. 
Table 1. Compositions and roughnesses of the pure Ti surface and the SLA, anodized and (Ca-P)coated Ti surfaces

\begin{tabular}{llllll}
\hline & & Pure Ti & SLA & Anodized & (Ca-P)-coated \\
\hline & $\mathrm{Ti}$ & $89.6 \pm 0.8$ & $90.1 \pm 0.8$ & $28.1 \pm 0.8$ & $31.9 \pm 0.8$ \\
& $\mathrm{O}$ & $10.4 \pm 0.8$ & $9.9 \pm 0.8$ & $66.6 \pm 0.4$ & $57.6 \pm 0.9$ \\
Compositions (atomic \%) & $\mathrm{Ca}$ & & & $3.8 \pm 0.4$ & $8.6 \pm 0.5$ \\
& $\mathrm{P}$ & & & $1.5 \pm 0.2$ & $1.8 \pm 0.3$ \\
\hline \multirow{2}{*}{ Roughness parameters } & $\mathrm{S}^{*}(\mu \mathrm{m})$ & $0.65 \pm 0.05$ & $1.73 \pm 0.25$ & $0.68 \pm 0.02$ & $1.74 \pm 0.08$ \\
& $\mathrm{~S}_{\mathrm{dr}}{ }^{\dagger}(\%)$ & $22.3 \pm 2.4$ & $101.5 \pm 21.1$ & $44.3 \pm 4.2$ & $91.2 \pm 9.1$ \\
\hline
\end{tabular}

${ }^{*} \mathrm{~S}_{\mathrm{a}}$ is the arithmetic average of the 3-dimensional roughness, which means the average height deviations of a given surface area.

${ }^{\dagger} S_{\mathrm{dr}}$ is a developed area ratio, which means the extent of surface enlargement if a given surface is flattened. 
Click here to download Table: 2012.12.24-Kang et al-Table 2.docx

Table 2. Primers for major bone matrix marker genes used to assess osteoblast differentiation in real-time PCR amplification

\begin{tabular}{|c|c|c|c|}
\hline Gene (NCBI ID) & Forward primer & Reverse primer & Product size (bp) \\
\hline $\begin{array}{l}\text { ALP } \\
\left(\mathrm{NM} \_000478.3\right)\end{array}$ & 5'-CCCACGTCGATTGCATCTCT-3' & 5'-AGTAAGGCAGGTGCCAATGG-3' & 100 \\
\hline $\begin{array}{l}\text { Bone sialoprotein } \\
\text { (NM_004967.3) }\end{array}$ & 5'-AAGGCTACGATGGCTATGATGGT-3 & 5'-AATGGTAGCCGGATGCAAAG-3' & 100 \\
\hline $\begin{array}{l}\text { Collagen type I } \\
\left(\mathrm{NM} \_000088.3\right)\end{array}$ & 5'-CAAAAAATGGGAGACAATTTCACA-3' & 5' -TCATGTTCGGTTGGTCAAAGAT-3' & 100 \\
\hline $\begin{array}{l}\text { Runx2 } \\
\text { (NM_001024630.1) }\end{array}$ & 5'-GCCTTCAAGGTGGTAGCCC-3' & 5'-CGTTACCCGCCATGACAGTA-3' & 67 \\
\hline $\begin{array}{l}\text { Osteocalcin } \\
\left(\mathrm{NM} \_199173.3\right)\end{array}$ & 5'-GAAGCCCAGCGGTGCA-3' & 5'-CACTACCTCGCTGCCCTCC-3' & 70 \\
\hline $\begin{array}{l}\text { Osteonectin } \\
\text { (NM_003118.2) }\end{array}$ & 5'-TACATCGGGCCTTGCAAATAC-3' & 5'-GGGTGACCAGGACGTTCTTG-3' & 100 \\
\hline $\begin{array}{l}\text { Osteopontin } \\
\text { (NM_000582.2) }\end{array}$ & 5'-CAGCCTTCTCAGCCAAACG-3' & 5'-TAACTGGTATGGCACAGGTGATG-3' & 100 \\
\hline $\begin{array}{l}\text { HPRT1 } \\
\text { (NM_000194.2) }\end{array}$ & 5'-GGTCAGGCAGTATAATCCAAAGA-3' & 5'-GGGCATATCCTACAACAAACT-3' & 131 \\
\hline
\end{tabular}




\section{Figure Legends}

Fig. 1. Proposed pathway for the promotion of cell attachment of PC12 cells by either laminin-2 or the LG1 domain and the DLTIDDSYWYRI motif (Ln2-P3) within the human laminin $\alpha 2$ chain. The Ln2-P3 motif as well as the laminin-2 and LG1 domain promote cell attachment through syndecan-1 by inducing phosphorylation and membrane localization of $\mathrm{PKC} \delta$. $\mathrm{PIP}_{2}$ : phosphatidylinositol 4,5bisphosphate, DAG: diacylglycerol, $\mathrm{IP}_{3}$ : inositol 1,4,5-trisphosphate.

Fig. 2. Animal surgeries were performed to install the investigated implants. (A) Two implants were inserted in the right rabbit tibia. (B) A schematic diagram explains the positions of the inserted implants. The inter-implant distance was about 8-10 $\mathrm{mm}$ from center to center. (C) Schematic diagrams show the arrangement of the investigated implant groups. Control is the pure Ti implant. SP means the SP-treated implant, and Ln2-P3 denotes the Ln2-P3-treated implant.

Fig. 3. Cell attachment, spreading, and migration of osteoblast-like HOS and MG63 cells seeded onto the culture plates coated with laminin, scrambled peptide (SP), and Ln2-P3. (A) Photographs of HOS and MG63 cells adhering to the culture plates coated with BSA (1\%), laminin $\left(1.3 \mu \mathrm{g} / \mathrm{cm}^{2}\right), \mathrm{SP}(21$ $\left.\mu \mathrm{g} / \mathrm{cm}^{2}\right)$, and Ln2-P3 $\left(21 \mu \mathrm{g} / \mathrm{cm}^{2}\right)$ for $3 \mathrm{~h}$. (B) Attachment of HOS and MG63 cells seeded on plates coated with laminin, SF, and Ln2-P3 for $1 \mathrm{~h}$ in serum-free medium. (C) Dynamic monitoring of MG63 cell responses to Ln2-P3. MG63 cells $\left(2 \times 10^{4}\right.$ cells per well) were seeded onto SP (21 $\left.\mu \mathrm{g} / \mathrm{cm}^{2}\right)$ - or Ln2-P3 $\left(21 \mu \mathrm{g} / \mathrm{cm}^{2}\right)$-coated wells of E-plates, and cell indices were continuously monitored every min for $3 \mathrm{~h}$; then, the indices were measured every $10 \min$ for $2 \mathrm{~h}$. Representative curves are an average of three replicate wells. (D) Spreading of HOS and MG63 cells induced by laminin, SP, and Ln2-P3. HOS and MG63 cells were seeded on plates coated with laminin (1.3 $\left.\mu \mathrm{g} / \mathrm{cm}^{2}\right)$, SP $\left(21 \mu \mathrm{g} / \mathrm{cm}^{2}\right)$, and Ln2-P3 $\left(21 \mu \mathrm{g} / \mathrm{cm}^{2}\right)$ for $3 \mathrm{~h}$ in serum-free medium. Cell area was measured by using Image-Pro Plus software. Data are expressed as a percentage of the value for cells 
seeded on BSA-coated plates for $3 \mathrm{~h}$. Data are expressed as the mean $\pm \operatorname{SD}(n=4)$. ANOVA: $p<0.05$. Pairwise comparisons: ${ }^{*} p<0.01$.

Fig. 4. Cell attachment of MG63 cells plated onto the modified Ti surfaces. SEM micrographs (A) and levels of cell attachment (B) of MG63 cells plated onto pure Ti surface and SLA, anodized, and (Ca-P)-coated Ti surfaces. SEM micrographs (C) and levels of cell attachment (D) of MG63 cells plated onto scrambled peptide (SP)- and Ln2-P3-treated pure Ti surfaces and anodized surfaces. Data are expressed as the mean $\pm \mathrm{SD}(n=3)$. ANOVA: $p<0.05$. Pairwise comparisons: ${ }^{*} p<0.01 ;{ }^{* *} p<$ 0.05 .

Fig. 5. Induction of osteogenic marker genes in Ln2-P3-treated osteoblast-like cells. MG63 cells ( 2 x $10^{5}$ cells/well) were seeded onto Ti discs ( $20 \mathrm{~mm}$ in diameter, $0.5 \mathrm{~mm}$ thick), which were placed on 12-well culture plates, coated with scrambled peptide (SP) or Ln2-P3 $\left(21 \mu \mathrm{g} / \mathrm{cm}^{2}\right)$, and cultured for 1 $\mathrm{d}$ and $7 \mathrm{~d}$ in serum-free medium. Expression of osteogenic marker genes, including type I collagen, bone sialoprotein, osteocalcin, and Cbfa- 1 was determined by real-time RT-PCR. RT-PCR for HPRT1 was used as a loading control. Data are expressed as the mean $\pm \operatorname{SD}(n=3)$. ANOVA: $p<0.05$. Pairwise comparisons: ${ }^{*} p<0.01 ; \stackrel{* *}{p}<0.05$.

Fig. 6. Alkaline phosphatase (ALP) expression and activity of osteoblast-like cells seeded onto Ln2P3-treated Ti discs. (A) ALP expression of Ln2-P3-treated MG63 cells measured by real-time RTPCR. The culture conditions were the same as described in the legend to Fig. 5. (B) Enzyme activity of ALP in Ln2-P3-treated MG63 cells. The culture conditions were the same as described in the legend to Fig. 5, except that MG63 cells cultured for $1 \mathrm{~d}$ and $3 \mathrm{~d}$ were used. ANOVA: $p<0.05$. Pairwise comparisons: ${ }^{*} p<0.01 ;{ }^{* *} p<0.05$.

Fig. 7. Light microscopy images of longitudinal sections of Ti implants from Ln2-P3-treated Ti 
implant-implanted rabbit tibiae. (A-C) H\&E staining of the wounds of pure Ti implant-implanted and scrambled peptide (SP)- and Ln2-P3-treated Ti implant-implanted rabbit tibiae for 4 weeks. Not enough new bone was formed at 1 week after implant insertion (A). More cancellous bone was found around the inserted implants after 2 weeks of healing (B). The new bone was mature in all groups after 4 weeks of implant placement (C). Insets are the magnified images of the squares indicated. Black arrowheads indicate the border between the new and existing cortical bone. (D and E) Levels of BIC ratio (D) and bone area (E) in wounds from pure Ti implants and scrambled peptide (SP)- and Ln2-P3-treated Ti implants in rabbit tibiae for 4 weeks. Data are expressed as the mean $\pm \operatorname{SD}(n=3)$. ${ }^{*} p<0.01 ; * * 2 p<0.05$.

Fig. 8. Light microscopy images for collagen and ALP of longitudinal sections of Ti implants from Ln2-P3-treated Ti implants in rabbit tibiae. Modified Goldner's Masson trichrome staining (A) and ALP histochemistry (B) of the wounds of pure Ti implants and scrambled peptide (SP)- and Ln2-P3treated Ti implants in rabbit tibiae for 4 weeks. Blue arrowheads indicate ALP staining of osteoblasts. 
Click here to download Figure: 2012.12.24-Kang et al-Figure 1.pdf

Fig. 1

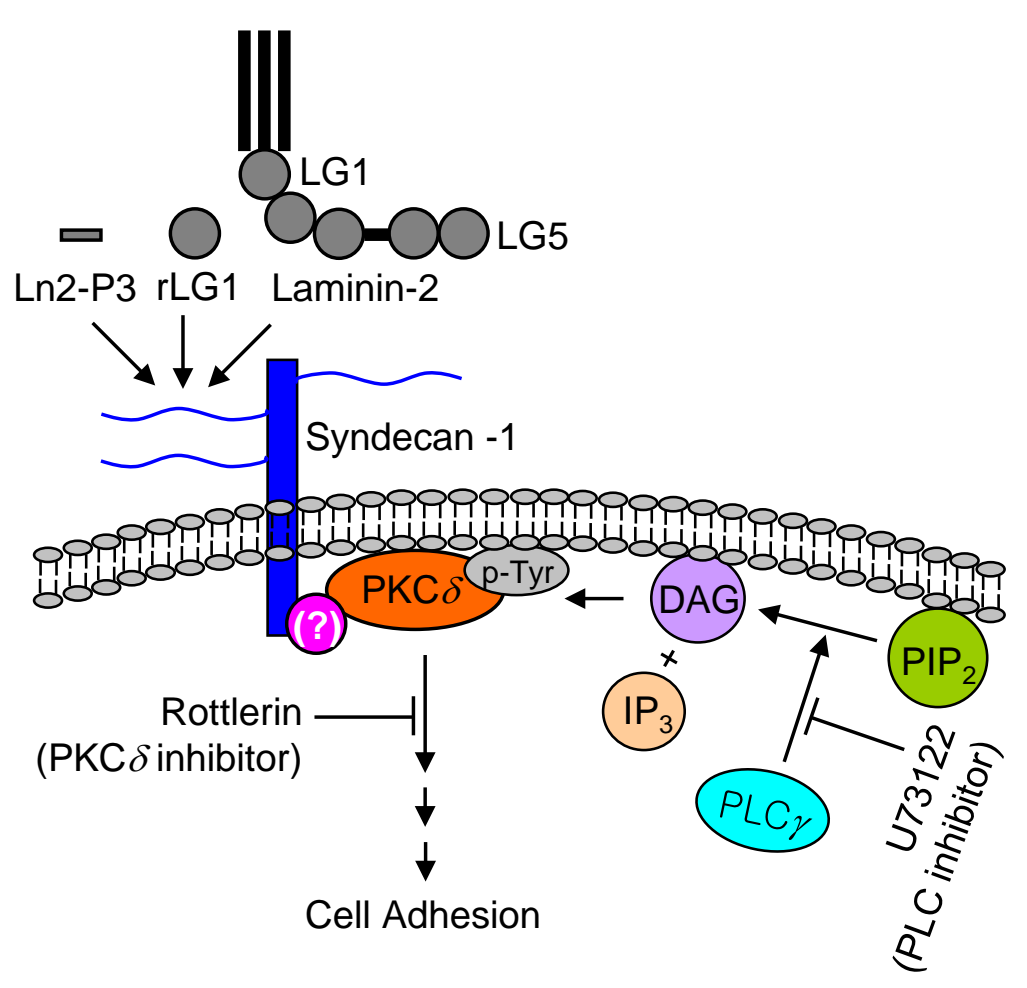




\section{Figure 2}

Click here to download Figure: 2012.12.24-Kang et al-Figure 2.pdf

Fig. 2

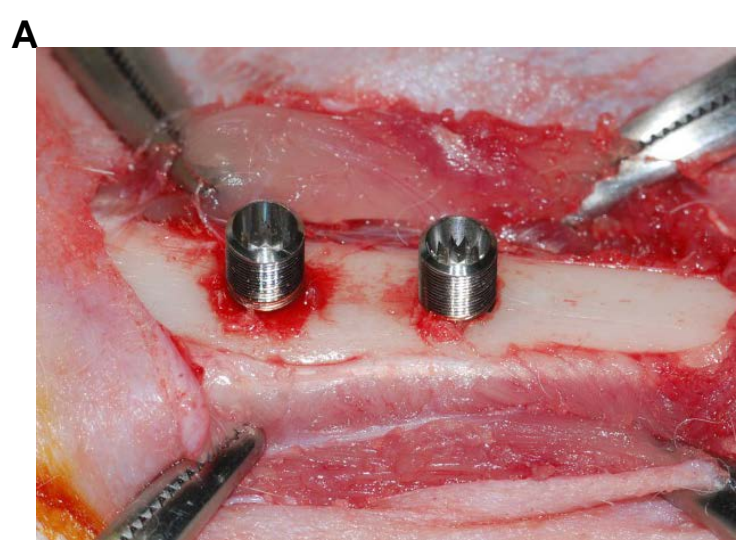

B

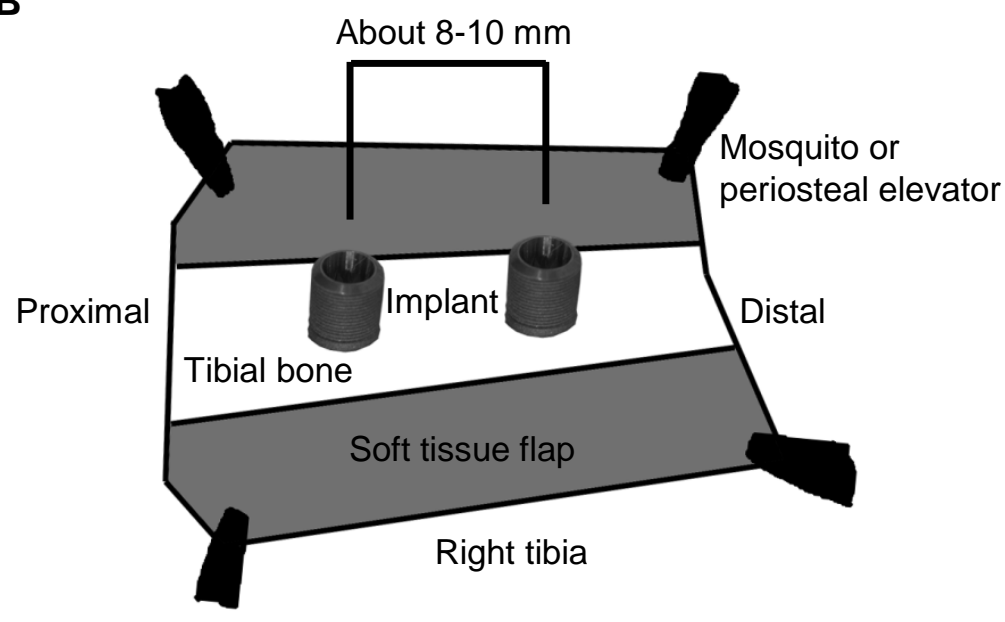

C

Right

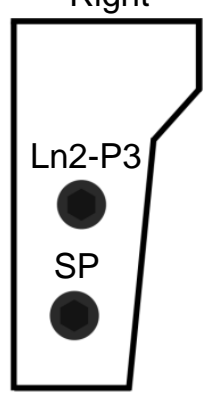

Left

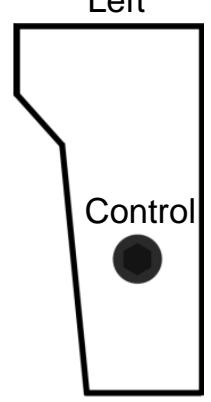

Right

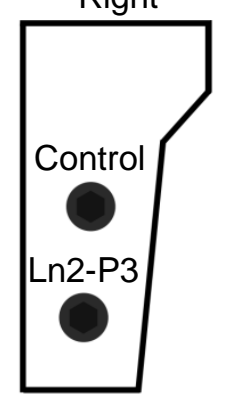

Left

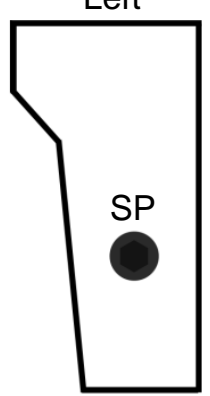

Right

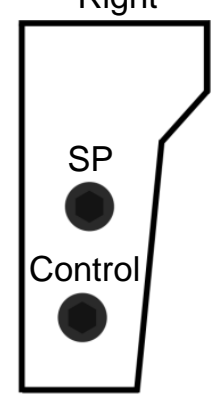

Left

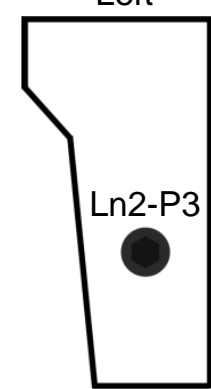


Click here to download Figure: 2012.12.24-Kang et al-Figure 3.pdf

Fig. 3

A

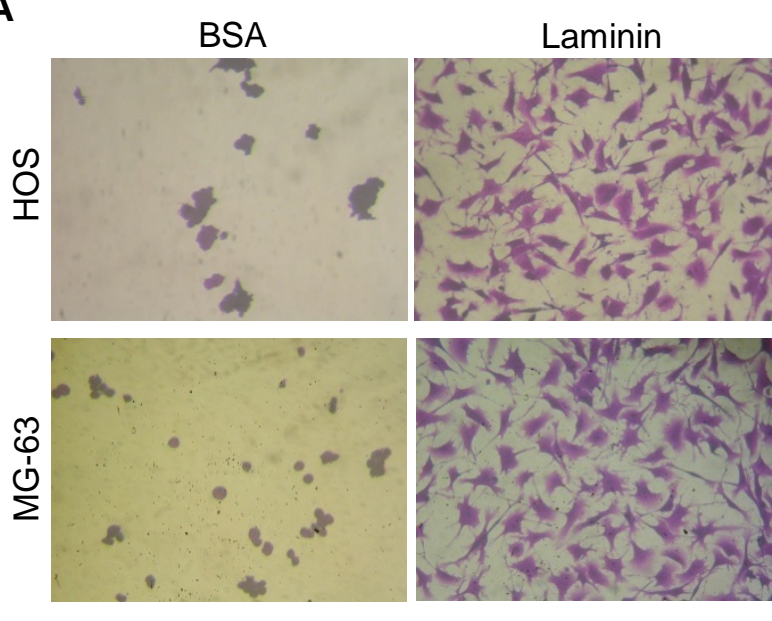

SP

Ln2-P3
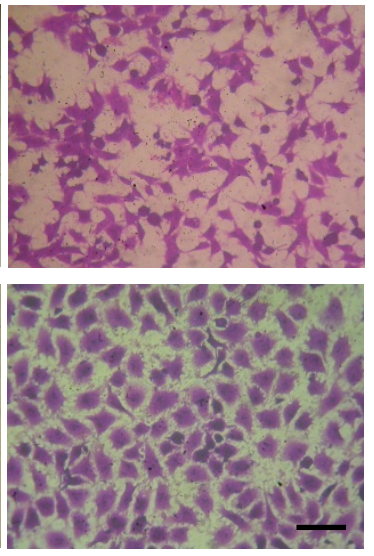

$100 \mu \mathrm{m}$

B

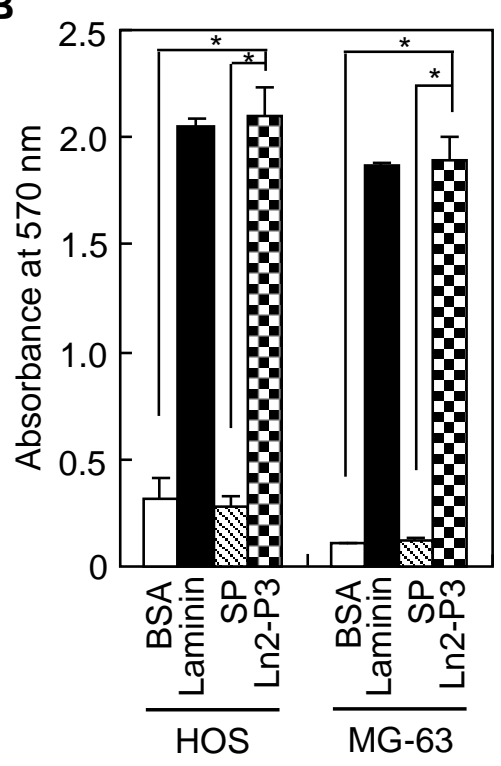

C

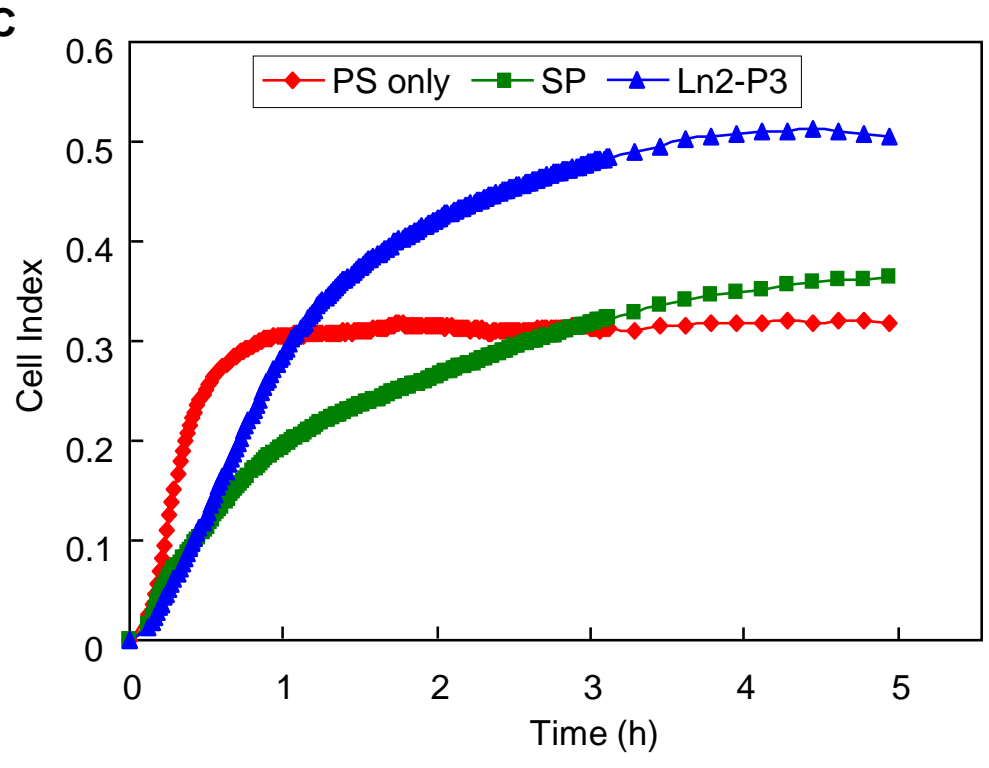

D

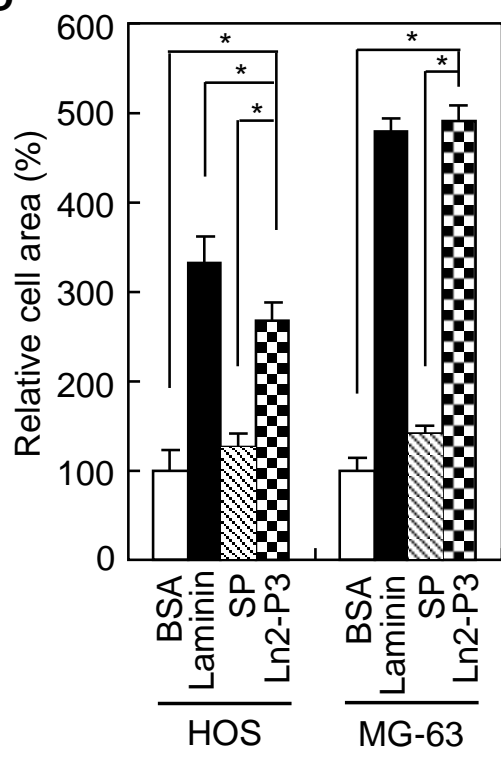


A
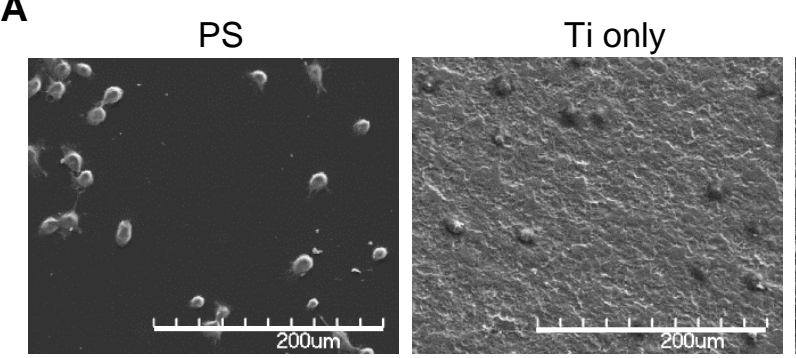

Ano

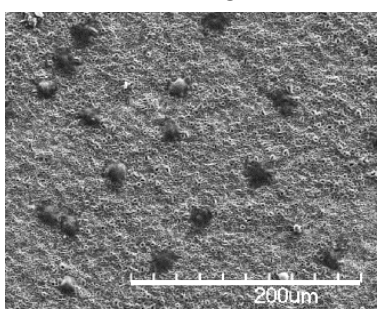

C

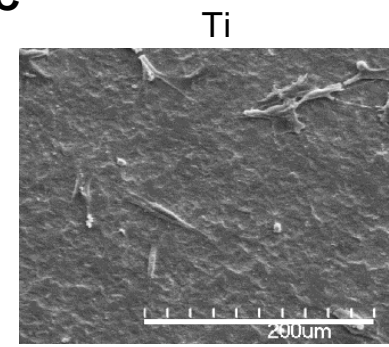

Ano
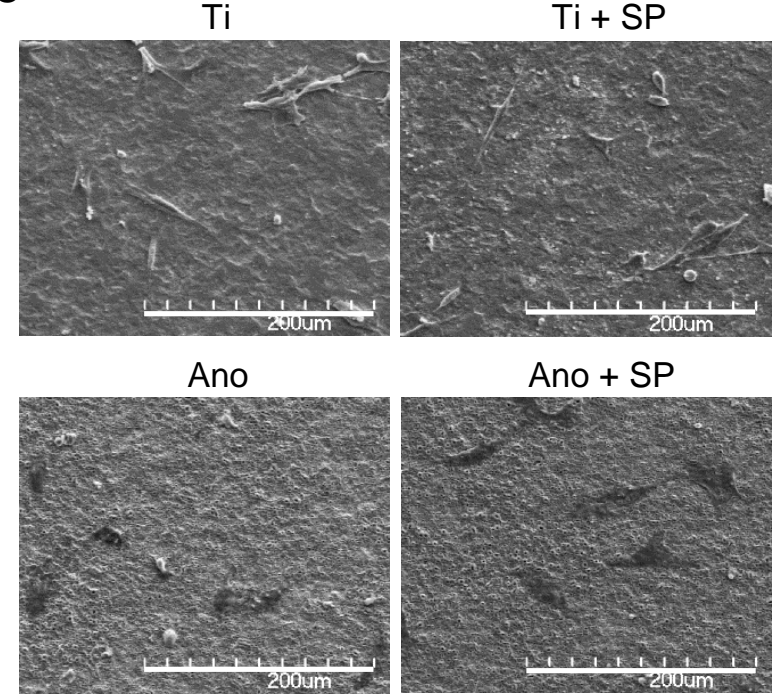

Ano + SP

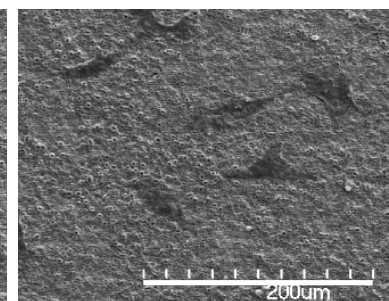

SLA

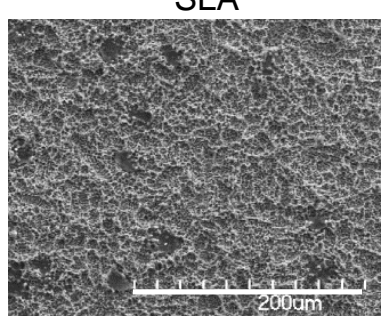

Ca-P

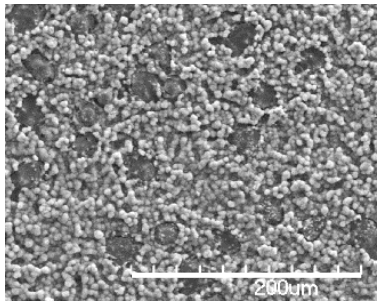

$200 \mu \mathrm{m}$

$\mathrm{Ti}+\operatorname{Ln} 2-\mathrm{P} 3$

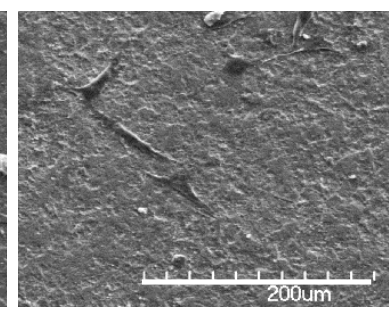

Ano + Ln2-P3

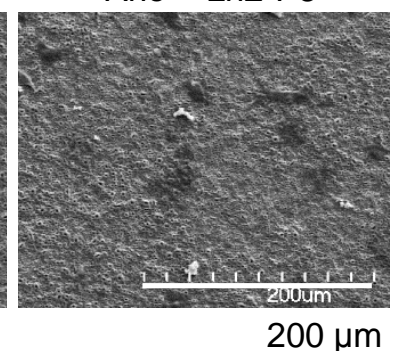

B

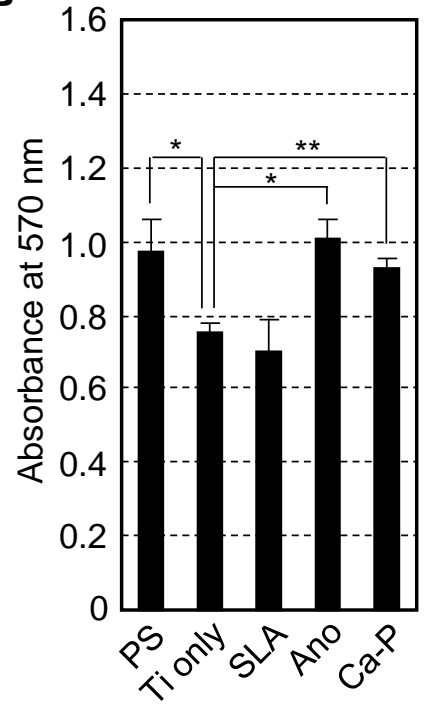

D

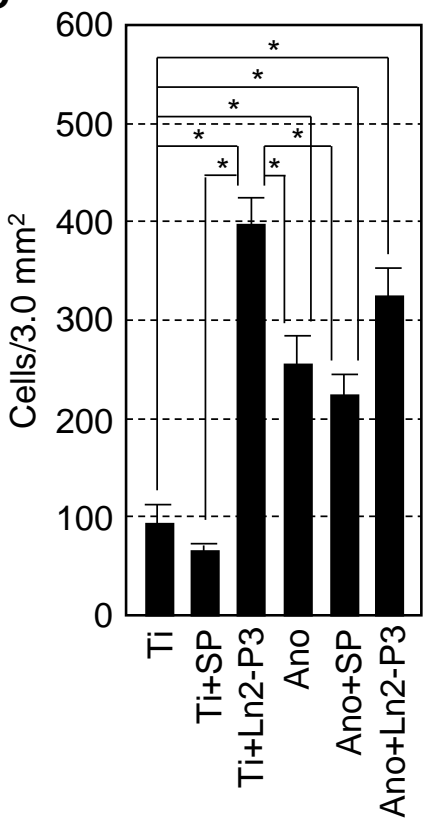




\section{igure 5}

Click here to download Figure: 2012.12.24-Kang et al-Figure 5.pdf

Fig. 5
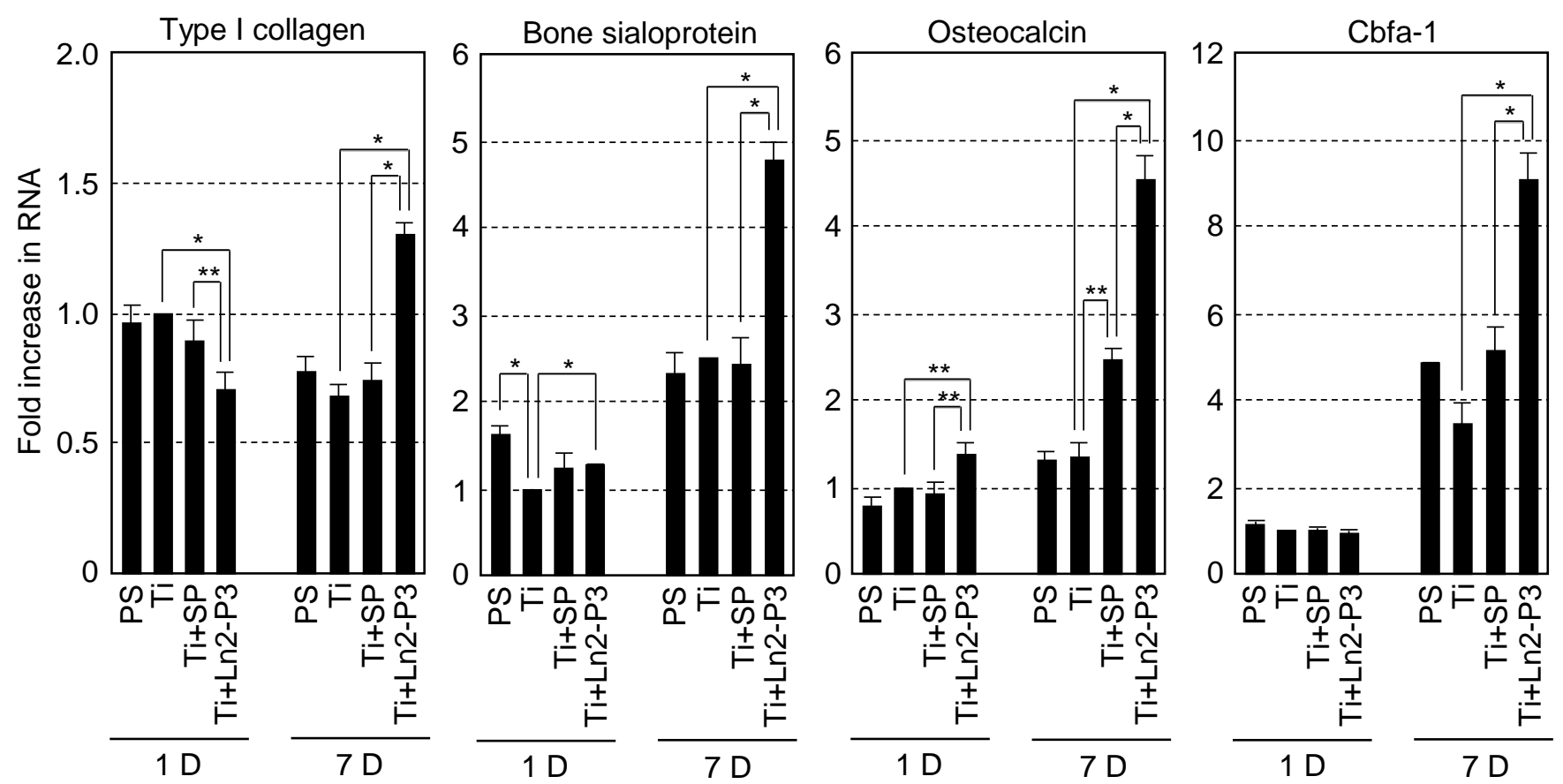
Fig. 6
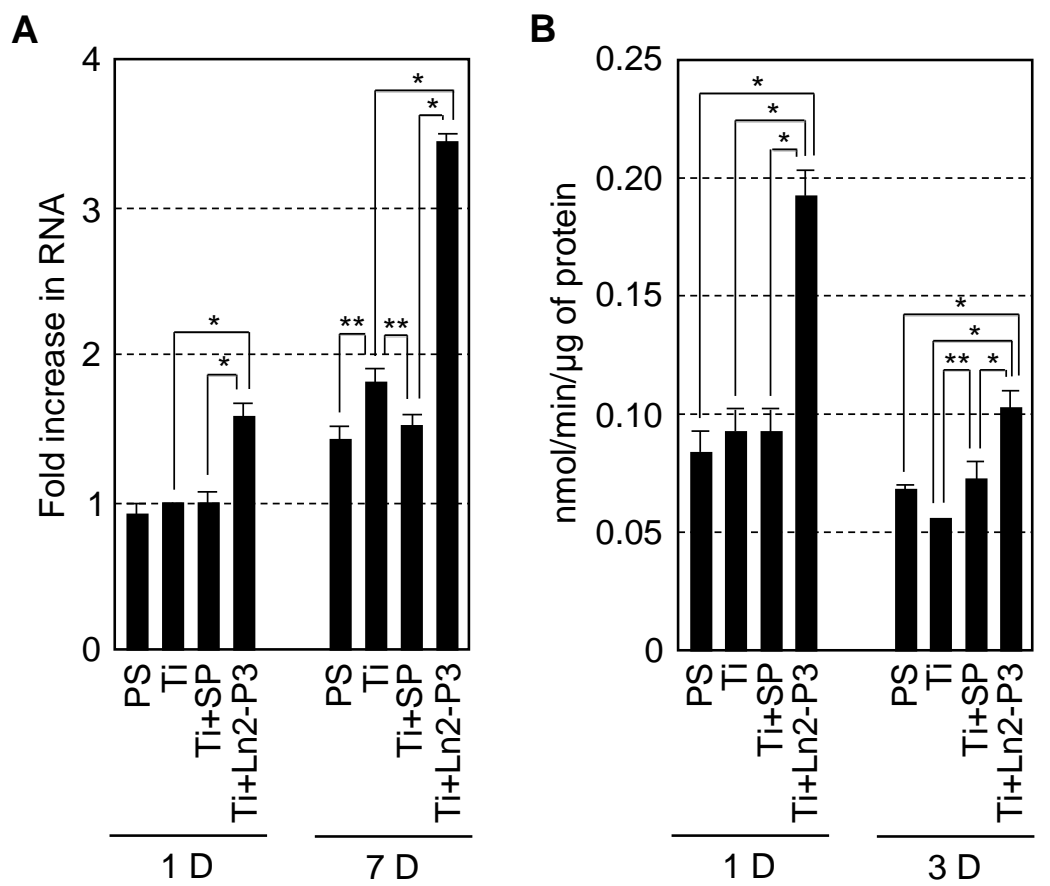


\section{igure 7}

Fig. 7

Figure: 2012.12.24-Kang et al-Figure 7.pdf

A
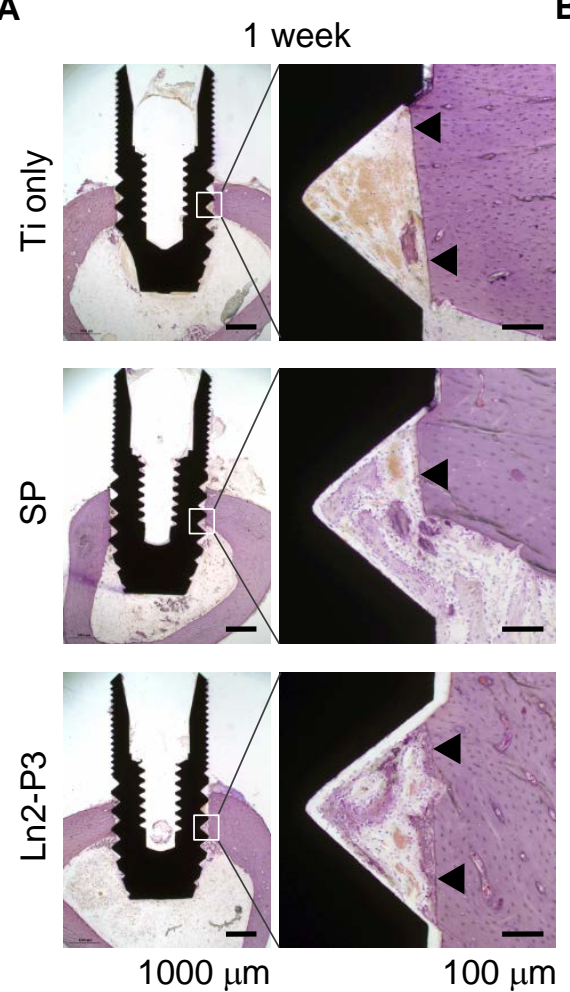

D

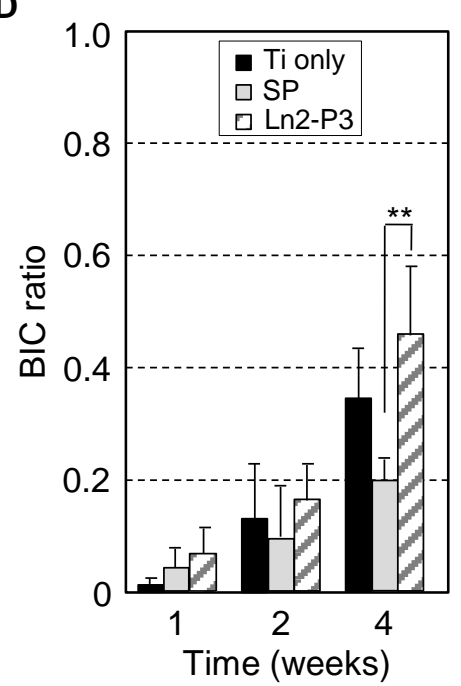

B

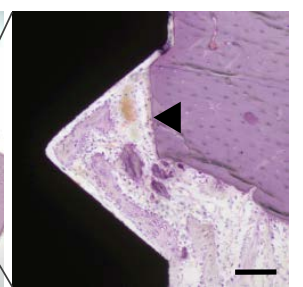

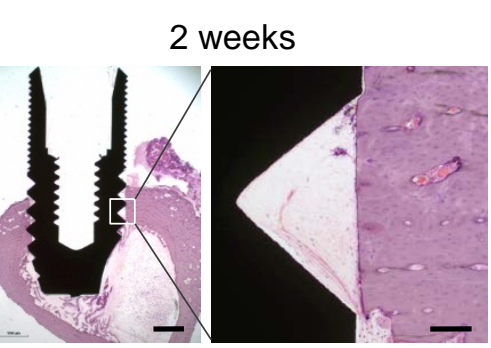
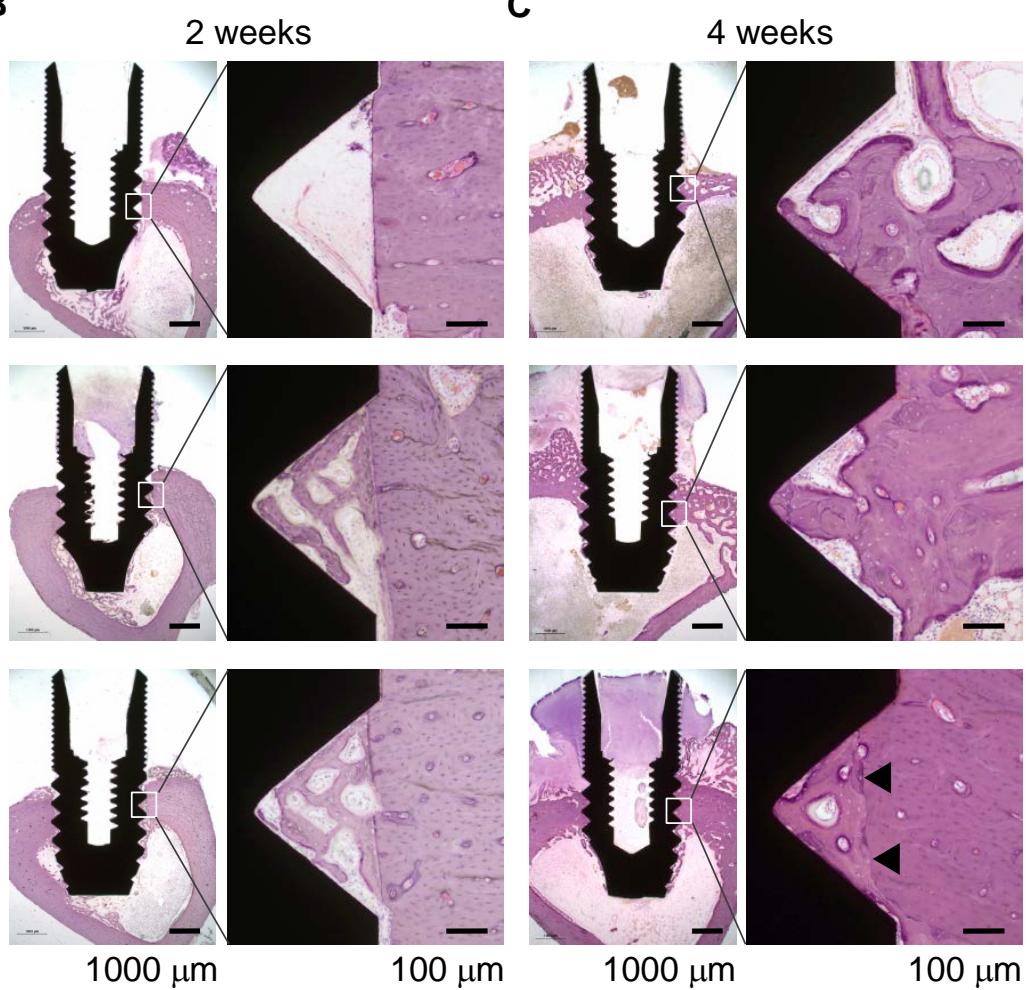

E

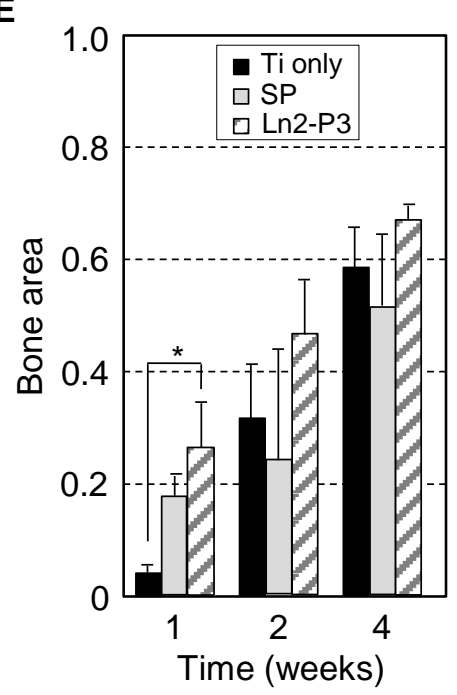


Click here to download Figure: 2012.12.24-Kang et al-Figure 8.pdf

Fig. 8

A
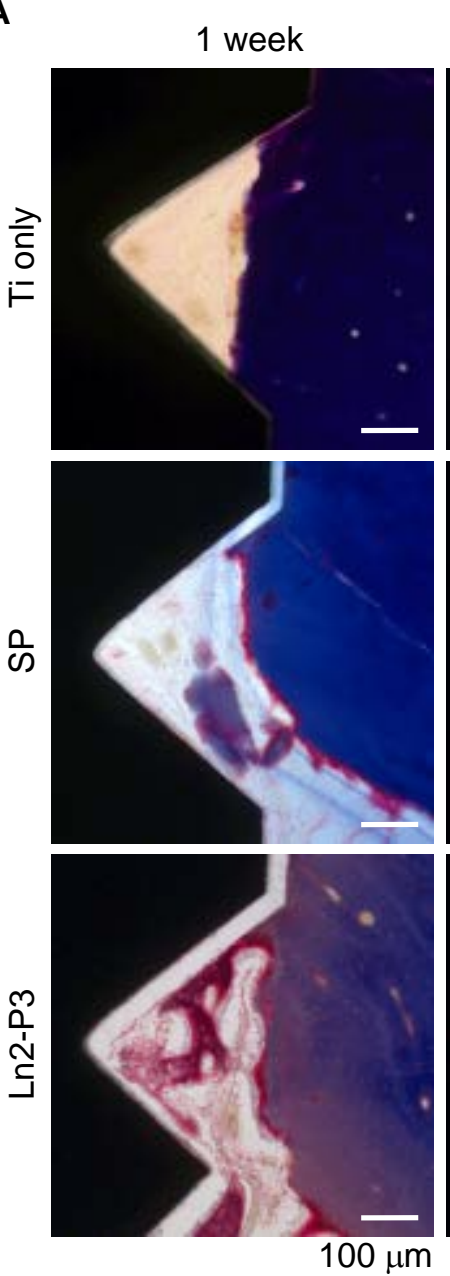

2 weeks
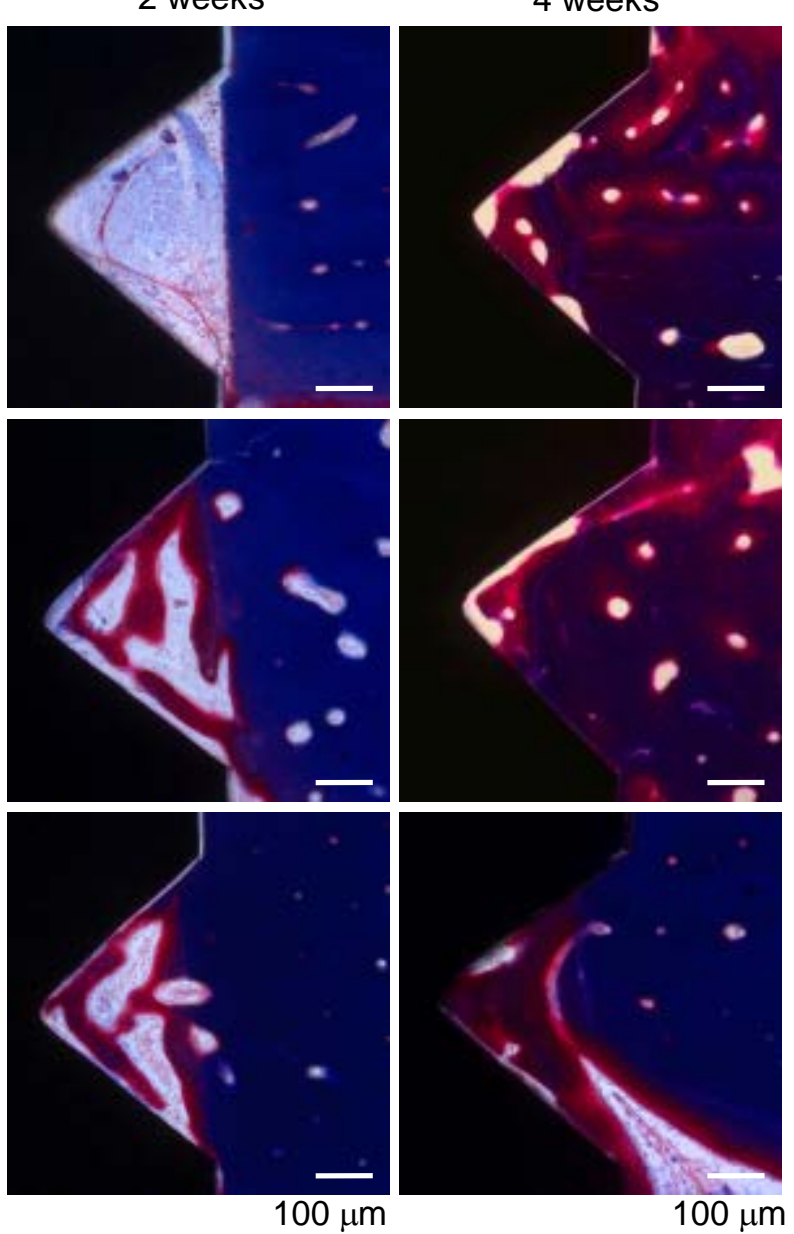

B

1 week
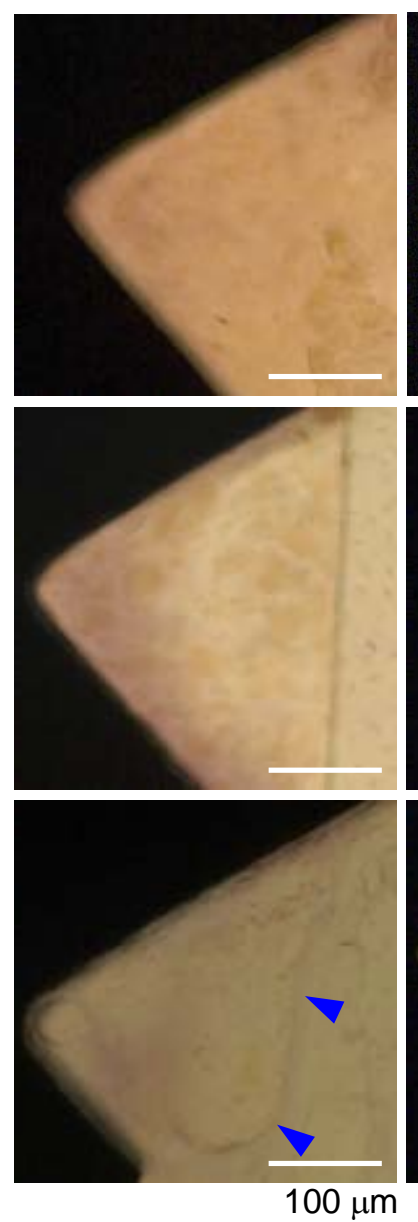

4 weeks

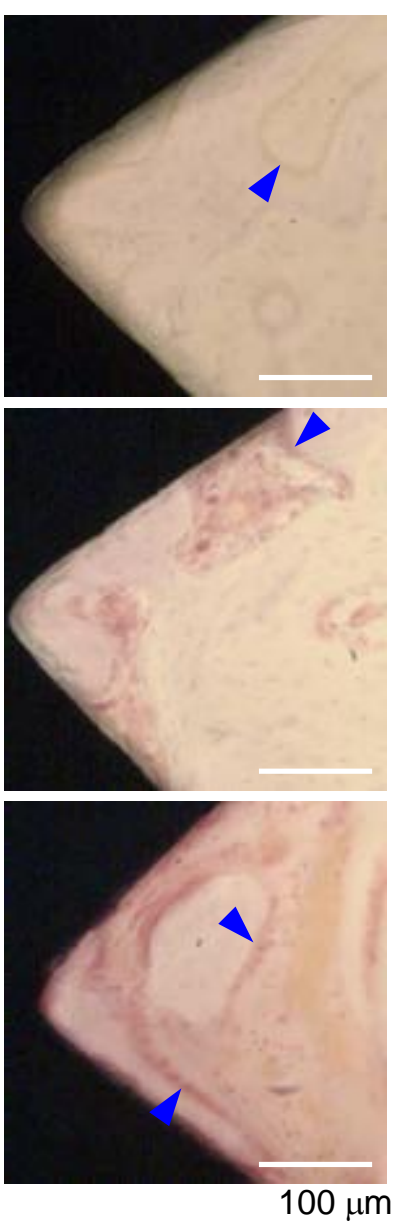

